\section{India's war on polio}

A campaign to vaccinate children against polio in India, one of the few remaining countries where the disease has not been eradicated, has been bolstered by a national polio project's decision to use a monovalent vaccine against the most prevalent type of the virus.

In Adampur, a back-country village of 7000 east of New Delhi, the polio surveillance coordinator for the World Health Organization (WHO) inspected vaccination efforts recently and worried about the likelihood of outbreaks.

"Polioviruses spread in polluted water," Dr. Ashok Talyan explained as monsoon rains hammered Uttar Pradesh province. The vast majority of the province's 230 million inhabitants live without access to hygienic facilities. "People use the sugar-cane fields as lavatories," Talyan said. "Now, with this rain, [water from] the fields will flood the village. The conditions are just about perfect here for polio and other water-borne diseases."

Even as the rain poured down, Talyan was surprisingly upbeat. "This year will be very different," he pledged. "I'm convinced we'll see far fewer polio cases than ever before."

Talyan's optimism stems from a decision by India's National Polio Surveillance Project last April to change tack on vaccinations. Instead of using trivalent vaccines to vaccinate children under I5 against all 3 types of wild poliovirus endemic in India, the children were vaccinated throughout the spring and summer rainy season solely against type $\mathrm{I}$, the most common form. A dose of monovalent type I vaccine immunizes roughly $80 \%$ of those vaccinated, double the rate for the trivalent vaccine.

"We're hitting the PI virus with a sledgehammer because PI is by far the biggest problem," said Talyan, a Ukrainian-trained MD seconded to the WHO from Uttar Pradesh's health department.

With an estimated ${ }^{6} 65$ million In-

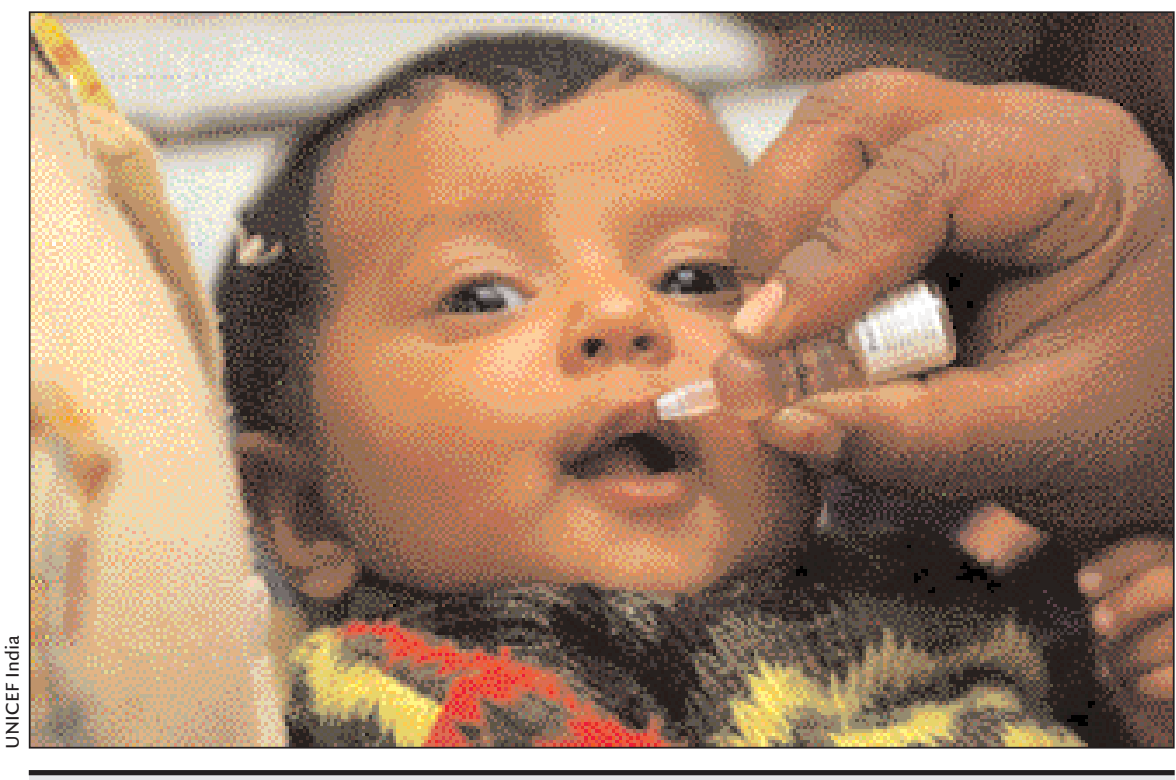

Last year 60\% of India's polio cases were in Uttar Pradesh.

dian children under 5 requiring repeated vaccinations, Uttar Pradesh and Bihar, a neighbouring province, are the key battlegrounds in what campaigners hope will be the end game in a \$4-billion worldwide polio eradication campaign launched by the WHO in I988. An estimated 2.3-million Indian health workers are involved in vaccination programs, and the number of polio cases dropped to I34 last year, from I6oo in 2002. Sixty percent of last year's cases occurred in Uttar Pradesh.

India's rapid progress, accompanied by similarly encouraging trends in Egypt and West Africa, led the WHO to suggest recently that "the stage is now set for global eradication of polio."

However, Indonesia, which had been polio-free since I995, has suffered a setback, reporting 225 cases of paralysis due to poliovirus since March. In August, 24 million Indonesian children under 5 were vaccinated.

Seen from ground level in Adampur, sustaining the momentum behind the WHO's optimism is a grindingly difficult, complex task. Every 6 weeks, more than 6000 local health officials and volunteers in Talyan's rural district of I.5 million must vaccinate every child, in every village. The vaccine is easily administered with eyedroppers, but must be kept chilled. That's a difficult task with temperatures that climb into the forties and an unreliable electrical service. The real problem, Talyan said, is reaching each of the young children in an area where parents widely suspect the government uses vaccination for population control.

On vaccination days, Talyan explained, surveillance teams are posted along roadways throughout the district so children can be checked and quickly vaccinated. In the villages, vaccinators go door to door, following minutely detailed maps that serve as a sort of epidemiologic census. For the 330 Indian physicians who fight polio full time, said Talyan, winning is a matter of national honour.

Not all polio experts are convinced they will succeed. At the University of Pittsburgh, Donald Henderson, who led the successful campaign to eradicate smallpox worldwide by 1977 before helping lead the successful campaign to eradicate polio in the western hemisphere by 1985 , views India's de- 
cision to focus on attacking the PI virus alone as a desperate measure.

"This has never been done before," Henderson says, noting there is a risk that type 3 polio could quickly reappear. Polio has proven far more intransigent than formerly expected in northern India, he adds. "An enormous job has been done. A lot of kids are not paralyzed because of it. But it's a little hard to envisage an endpoint."

As if to lend credence to Henderson's fears, 2 new cases of type 3 virus were identified in Uttar Pradesh in July. At the head office for the National Polio Surveillance Project in New Delhi, the project's technical coordinator, Dr. Sunil Bahl, seemed unperturbed by this development. The good news, Bahl said, is none of the I8 cases of type I virus reported in India this year appeared after the vaccinators began targeting it alone. In August, Bahl said, vaccinators switched back to trivalent vaccines not because of the new type 3 cases, but because "we planned to do that all along."

On the ground in Adampur, Talyan admits the pressure is intense. As the summer rains hammered down, Talyan urged vaccinators to catch every child. "This could be the year we finally smother the problem," he said. "But we won't know how we've done until monsoon season ends in October." - Paul Webster, Adampur, Uttar Pradesh, India

DOI:I0.I503/cmaj.05118I

\section{C. difficile may have killed}

\section{0 in Quebec: study}

An earlier report was published at www.cmaj.ca on Sept. 22, 2005.

$\infty \quad$ See also pages I037, I049.

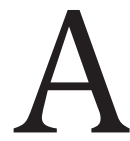

s many as 2000 patients may have died in Quebec in 20032004 during an outbreak of Clostridium difficile, which the majority of those patients contracted in hospital.

The figures - far higher than any that the province of Quebec officially re-

\section{Two thousand deaths is the most} plausible number based on the data available. - Dr. Jacques Pépin leased - are an extrapolation from a research study that infectious disease consultant Dr. Jacques Pépin conducted at the Centre Hospitalier Universitaire de Sherbrooke. The $C$. difficile outbreak hit the institution hard, and Pépin reported in August 2004 that his hospital lost at least Ioo patients over that period (CMAJ 2004;I7I[5]:436).

At the time, Pépin predicted that more than Iooo patients across the province likely died within 30 days of contracting the infection in 2003-2004. With his colleagues Louis Valiquette and Benoit Cossette, the Sherbrooke physician has now completed a cohort study to measure mortality attributable to hospital-acquired $C$. difficile at their institution during the same period. Their study of 56ra patients compared those with $C$. difficile to others with similar underlying medical conditions. They found that $23 \%$ of patients who developed $C$. difficile-associated diarrhea died within 30 days, compared to $7 \%$ of the control group. The Sherbrooke mortality rate is identical to that measured by a surveillance system Quebec created to monitor $C$. difficile after news of the outbreak broke.
The cumulative I-year mortality rate was $16.7 \%$, Pépin found.

Since the provincial database reported 773I cases of hospital-acquired C. difficile during fiscal 2003/04, and preliminary results suggest a similar incidence in 2004/05, Pépin assumes I4 000 cases in Quebec for 2003-2004. Based on his results in Sherbrooke, and allowing for a I-year mortality rate of slightly lower than $16.7 \%$, Pépin estimates that 2000 people died as a result of the epidemic.

The findings surprised even himself, Pépin told CMAJ. "Two thousand is the most plausible number based on the data I have," he says.

But the head of the Public Health Institute of Quebec quickly rejected the figure, although he acknowledged the province does not know how many people died from $C$. difficile in the 2003/2004 period because the province only began collecting data in August 2004 and is not reviewing charts or discharge reports before that date.

"That extrapolation is too high," Dr. Alain Poirier said in an interview. "Is it 500 , 1000 or 2000 - it is difficult to say. For sure, it's not 2000. That we know."

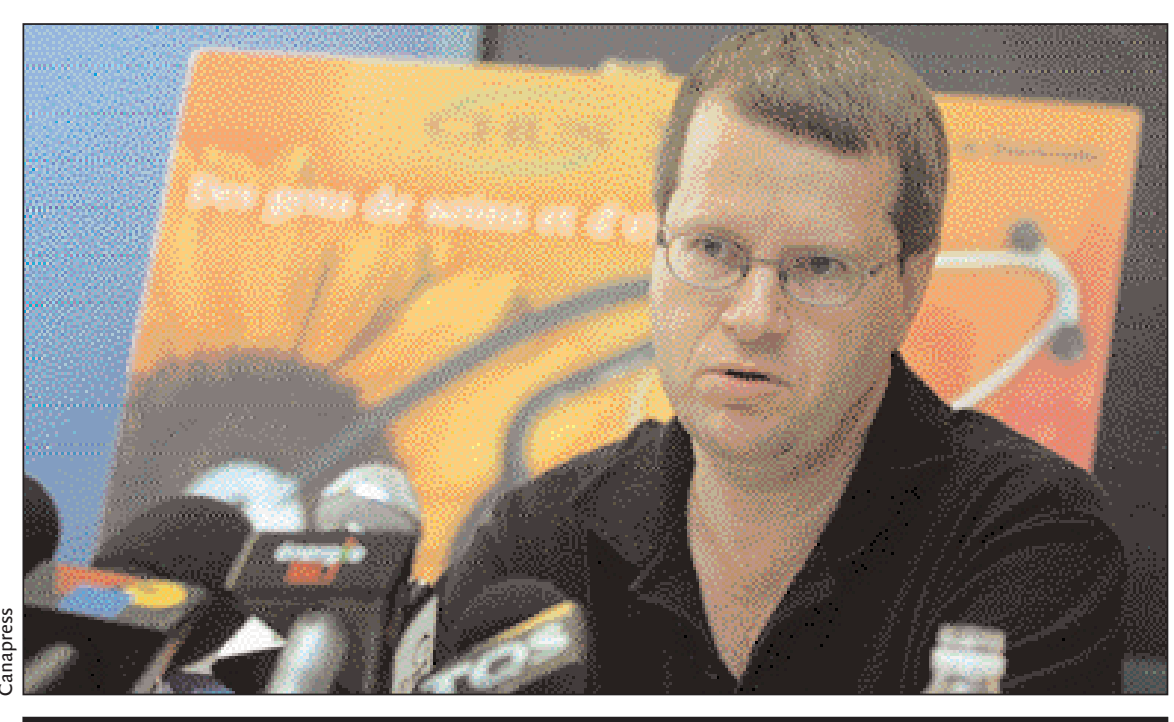

Dr. Jacques Pépin discusses the extent of the $C$. difficile epidemic in Quebec. 